\title{
Metamorphosis into mother after 35 years of age: a study of Grounded Theory*
}

\author{
A metamorfose na mãe após os 35 anos de idade: um estudo de Grounded Theory \\ La metamorfosis en la madre después de los 35 años de edad: un estudio de Grounded Theory
}

How to cite this article:

Santos MAF, Lopes MAP, Botelho MAR. Metamorphosis into mother after 35 years of age: a study of Grounded Theory. Rev Esc Enferm USP. 2019;53:e03485. DOI: http://dx.doi.org/10.1590/S1980-220X2018033403485

\section{Maria Anabela Ferreira dos Santos ${ }^{1}$ \\ D Maria dos Anjos Pereira Lopes ${ }^{1}$ \\ D Maria Antónia Rebelo Botelho ${ }^{1}$}

* Extracted from the thesis: "The process of woman's metamorphosis above thirty-five years in mother - a specific theory of the situation”, University of Lisbon, 2018.

${ }^{1}$ Lisbon School of Nursing, Research and Development Unit in Nursing, Lisbon, Portugal.

\section{ABSTRACT}

Objective: To understand the transition process of women through maternity status after 35 years of age. Method: The methodology of constructivist Grounded Theory was used in the design of research, data collection and analysis. Results: The results allowed the construction of a comprehensive model of the transition to motherhood experience after the age of 35, called "Metamorphosis in Mother". This process integrates several categories, being addressed in this article only two of them: "Confronting the dark side" and "Caring for herself". Conclusion: From the results, the difficulties experienced by the mothers around the 2nd month are highlighted, which revealed an obscure side of motherhood unknown to mothers and the need to take care of themselves to overcome these difficulties.

\section{DESCRIPTORS}

Maternal Age; Social Identification; Obstetric Nursing.
Corresponding author:

Maria Anabela Ferreira dos Santos

Lisbon School of Nursing

Av. D. João II, Lote 4.69.01, Parque das Nações

1990-096 - Lisbon, Portugal

afsantos@esel.pt
Received: 08/16/2018

Approved: 10/31/2018 


\section{INTRODUCTION}

The occurrence of motherhood after the age of 35 is a trend that has been observed in developed countries ${ }^{(1-3)}$, including Portugal ${ }^{(4)}$ where the average age of the mothers at the birth of the first child was 25 years in 1960 and reached 30.3 years of age in $2017^{(5)}$. It is in the age group 35-39 that there has been a greater growth, expressing an increase of the average age of the mothers of $6.9 \%$ in 1981 , to $24.9 \%$ in $2016^{(5)}$. The postponement of maternity has direct consequences on the decline in fertility rates, due to the shorter reproductive time remaining and the decrease in the fertility of women ${ }^{(2)}$. Demographic trends in most Organisation for Economic Cooperation and Development (OECD) countries show a decline in fertility and an increase in life expectancy ${ }^{(6)}$, with fertility rates below 2.1, i.e. the threshold needed for the replacement of the previous generations and maintain a population size. Portugal followed the same trend: in 1982 it was the first year in which the average number of children per woman was below the generational substitution threshold, and since 1994, this index has persistently remained below the threshold of 1.5 children considered critical for the sustainability of any population ${ }^{(4)}$. Low fertility rates cause job-related concerns in the labor market and government spending on pension, health and wellness services ${ }^{(7)}$. Being a mother at this extreme of the reproductive life poses risks to health, because the organs in general, and especially the reproductive ones, are in a phase of decline of their functions ${ }^{(8)}$. Pregnancy at the end of reproductive life is associated with an increase in maternal-fetal complications ${ }^{(9)}$, and it has been scientifically proven that the risks of maternal and fetal complications increase with maternal age ${ }^{(10)}$. However, greater psychological maturity associated with better social and health conditions may determine favorable outcomes ${ }^{(11)}$.

Maternity profoundly changes women's lives, and it is considered the major developmental transition throughout the life cycle ${ }^{(11-12)}$. In the transition to motherhood women are aware of the irreversibility of the process, they become involved in it, they have the notion that it involves changes in their lives that in turn will determine differences in their way of being, feeling and being thereafter. It is a transition that simultaneously results from change and causes change ${ }^{(13)}$. Becoming a mother means moving from a known reality to another unknown ${ }^{(12)}$. This transition implies that the woman restructures her goals, behaviors and responsibilities to achieve a new concept of self. Transitions can be facilitated or hampered by women's particular conditions, cultural beliefs and attitudes, socio-economic status, preparation and knowledge, and community and social conditions ${ }^{(11-12)}$. Furthermore, transitions are dynamic and are characterized by phases, milestones and turning points and can be defined through processes and/or results ${ }^{(14)}$. The transition to motherhood is triggered by a critical event - the finding of pregnancy or its anticipation, and in this case the desire or idealization of being a mother. It is a shift from a stable state to another stable state, with key moments and turning points that occur throughout the process that will require new patterns of response in terms of capabilities, relationships and roles, which in turn will lead to certain results. The diagnosis of pregnancy and its acceptance represents one of those key moments that will determine changes that will require new patterns of response to the expectant mother. The conditions of the woman or the context in which the transition to motherhood occurs can be either facilitating or hindering the process and the outcome of the transition. Thus, to understand the experiences of motherhood and for a health intervention, in particular from a nursing perspective, it is important to know the personal and contextual conditions of the woman in whom the transition occurs. As in any nursing intervention, it is important to identify the factors related to the person and the environment that surround the pregnant woman and the maternity, as well as what the person knows about the process of pregnancy and maternity. For an individualized intervention it is significant, for example, to know the meaning that women attribute to motherhood, the cultural beliefs and attitudes associated with the motherhood of women and the family, parity, level of education, socioeconomic status, family support and social, health care network. The experiences of parents, spouse/partner family, and friends' support and beliefs are also conditions that may positively or negatively influence the transition process and outcome. Life goals, fears and desires related to life and the specific phenomenon of motherhood are not always taken into account in the daily practice of caring for women in this transition.

The present study is part of a larger research that had as its starting point the following research question: How is the process of transition to motherhood developed after the age of 35? As a result of this, the following objectives were outlined: Identify the key moments of the transition process in the maternity after the age of 35 ; Understand the facilities and difficulties in the performance of the maternal role experienced by mothers after 35 years; Understand the strategies/interventions that facilitate the adoption of the maternal role most frequently used by mothers after the age of 35; Recognize the results of a successful transition to the maternal role experienced by mothers after the age of 35 .

\section{METHOD}

\section{Design OF STUDY}

As a methodological reference, the constructivist perspective of Charmaz's Grounded Theory $(\mathrm{GT})^{(15)}$ was used. According to this perspective, care was taken to explain the investigator's preconceptions because they are not a neutral observer - their preconceptions and privileges influence and shape the analysis. The researcher cannot separate themselves from their experiences or research or be objective about the data; on the contrary, they makes subjective interpretations of the data, based on their perspective, privileges, positions, interactions or geographical locations ${ }^{(15)}$. As a result, the investigator's findings are not representative of a truth, of a discovered reality, but of interpretations of multiple 
realities mutually constructed by the investigator and the investigator/participant ${ }^{(16)}$. In the constructivist perspective knowledge is seen as "constructed in a process of social exchange" ${ }^{(17)}$, in which the presence of the researcher in the product of research is neither neutral nor undesirable. Their voice in the final outcome of the investigation should not be excluded, avoided or hidden ${ }^{(18)}$. According to this perspective the role of the participants is not a passive role but, on the contrary, the final theory generated is really a co-construction of the researcher and participants or the construction of the researcher about the constructions of the participants ${ }^{(18)}$. In our study, the systematic review of the literature, the identification of the sensitizing concepts that initially guided the data collection/elaboration of the questions, the theoretical sampling performed, the diversity of data collection methods, awareness of the active role of the researcher and of their opinions, preconceptions about the theme/phenomenon, the non-use of a paradigm model in data analysis, as well as the active participation of the subjects in the production of the narratives, the capture and elicitation of the collected photographs and the validation of the concepts that were emerging, are in accordance with the constructivist perspective ${ }^{(15)}$. The lenses of symbolic interactionism helped in the co-construction of meanings grounded in the data that emerged.

\section{Population}

The 21 participants were between the ages of 35 and 47 , with the majority in the age range of 35 to 39 years old, followed by participants between the ages of 40 and 44 . As for nationality, the 21 participants comprised 6 nationalities, with the Portuguese being the most expressive. As far as the educational qualifications were concerned, 7 of the 21 participants had a bachelor's degree and the same number had secondary education. As for parity, for most participants this was their first or second child. Regarding the type of delivery, 11 of the participants had a eutocic delivery, 9 underwent a cesarean section and one forceps. As for the religion, the majority of the participants were Catholic, followed by Adventists and a few affirmed to be agnostic.

\section{Data Collection}

In order to collect data, we used the semi-structured interview, the Photovoice method ${ }^{(9,19)}$ and field notes. The question used in the semi-structured interviews was: "How do you describe your experience of motherhood?" Data collection was performed between 2013 and 2016.

For the selection of participants, in the initial sampling we defined inclusion criteria, and later the theoretical sampling was used.

The sensitizing concepts that helped us to define the inclusion criteria for the initial sample were: pregnancy risk, maternity experience, absence of maternal or fetal/ newborn pathology, and eutocic delivery. In order to obtain initial sampling at the beginning of the study, we defined the following inclusion criteria: mothers over 35 years of age, primiparous or multiparous, pregnancy without disease (previous or acquired), eutocic delivery, newborn without pathology or malformation, women providing richness of information not only by experiencing the phenomenon but also that they would like to share their experience and that they would agree to participate in the study by signing the informed consent.

\section{Data ANALIYSIS AND TREATMENT}

All interviews were recorded in audio, assigned a code number - for example E1 meant interviewee number 1 - and transcribed into a verbatim which were initially introduced and analyzed with software NVivo 11 and later manually. The analysis of the photographs was subjected to the same process of analysis of the interviews, that is, after the photos were taken, their elicitation was performed, that is, the narrative about the photos was transcribed in verbatim for further analysis ${ }^{(19)}$. In the data analysis, the method of constant comparisons in the initial coding, focused and theoretical, was used. Twenty-six interviews were carried out with 21 participants, either in the hospital or at home, with a variable duration between 30 and 120 minutes, and 35 photographs of 6 participants were collected. In summary, the investigation followed the following steps: initial sampling with initial coding, focused coding and last theoretical sampling and theoretical coding. After formulating the research question, we drew up the study and asked for the ethical consent of the various institutions and participants, we defined the inclusion criteria for the participants and carried out the first phase of data collection that was transcribed for verbatim. In the initial coding phase, the transcribed data were analysed line by line, coded using preferably the in vivo codes, maintaining the gerund, interacting and comparing the data among each other and elaborating memos. In the focused coding phase, we continued to interact and compare the data, identify the most significant data, construct categories and subcategories. As recommended by the GT method, the analysis and discussion of the data was performed simultaneously with the data collection and guided the selection of new participants. In the last phase of theoretical sampling and theoretical coding, after each interview participants were intentionally selected using the "snowball" method and the social networks, aiming to deepen certain categories or aspects that appeared during the previous phases. In this last phase we compared the categories to each other, we identified the central category and the key concepts around which the theory was organized, as well as the relationship between the central category and the other categories. The theoretical saturation of data was reached, when new categories did not emerge, that is, when the categories presented robustness and no new theoretical insights appeared that allowed to deepen the phenomenon under study. In order to ensure the quality and reliability of the study, we performed the rigor evaluation, using the criteria of credibility, audibility and fit/transferability ${ }^{(20)}$. These were also complemented with the criteria recommended by Charmaz to evaluate studies carried out with the GT methodology: credibility, originality, resonance, utility and aesthetics ${ }^{(15)}$. 


\section{ETHICAL ASPECTS}

Ethical consent of the various institutions involved were asked (school/university, hospital and National Commission on Data Protection), as well the request of ethical consent to the participants for the use of the photographs and the interviews.

\section{RESULTS}

The following categories emerged in the larger study and integrate the transition process to motherhood after the age of 35, designated for Metamorphosis in Mother: Raising awareness of the desire to be a mother, Choosing the right moment, Confronting the dark side, Caring for herself and Being another. In the present article we present only the results obtained from two categories - Confronting the dark side and Caring for herself.

The category Confronting the dark side revealed a more obscure phase of motherhood, more somber, difficult and sometimes sad, oppressive, disturbing, less referred and therefore unknown to the participants. As found in Figure 1, the solitary finding on the obscure side of maternity was identified by the participants as being assigned to the torment of breastfeeding, the requirement of focusing on the care of the baby, the fear of marital withdrawal of the partner, the misunderstanding of their fatigue, fear of being harmed in the professional career, the realization that caring for the children continues to be a social role attributed to women and also the withdrawal of social life.

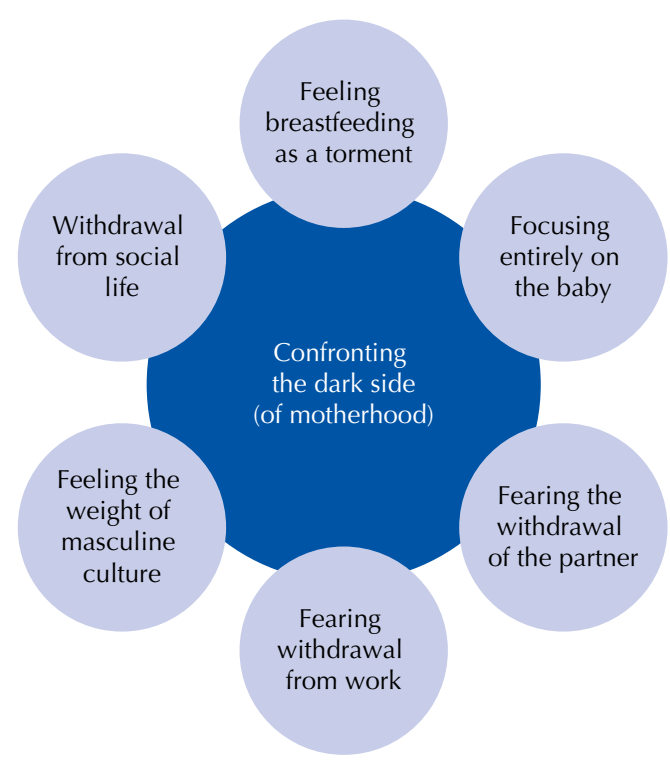

Figure 1 - Category Confronting the dark side and its subcategories.

About the Torment of breastfeeding, one participant commented on a photograph showing a breastfeeding cushion (Figure 2): I was nursing (...) with her in my arms and with tiredness and when I went to get up I was numb and I fell! (...) that worried me so much, so much, so much ... what could have happened to the baby ... I let myself sleep; the tiredness was so much and I did not notice that it was dormant. That stirred a little bit with me ... never again, this cannot happen again because now I've been able to catch him, but there may be a day that I cannot catch him. This thing of letting me go, having become so tired, that marked me! (E 20).

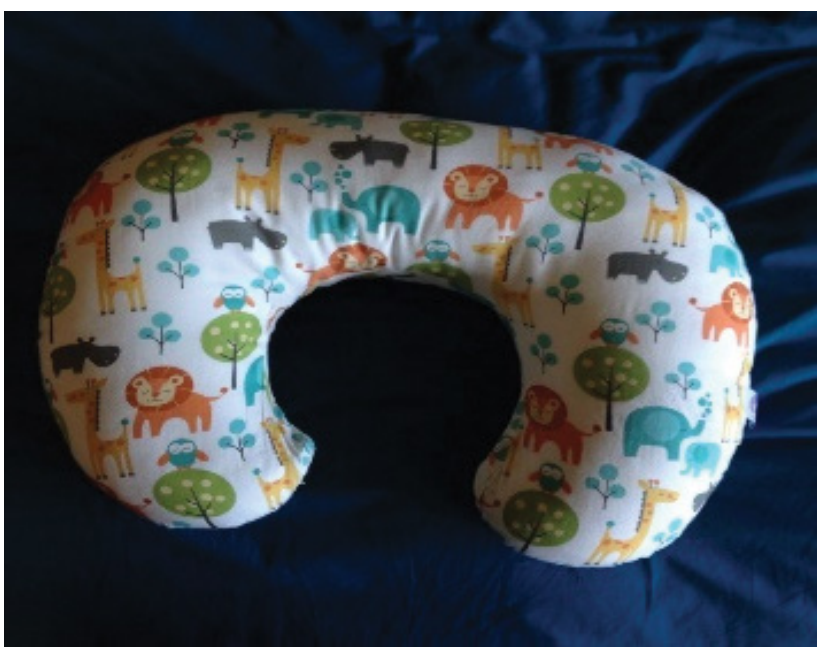

Figure 2 - Illustrative photograph of Breastfeeding Torment.

Another obscure side of motherhood that emerged in the participants' discourses was the Confrontation with the urgent need for total focus on baby care, which refers mothers in the first three months of the child's life to a forced closure at home. Baby care took precedence over all other chores and roles because, as one mother put it: everything goes around for the baby (E1).

Fearing the withdrawal of the partner - it was unanimously mentioned by the participants that the fear of tiredness in the first months of maternity could be reflected in the couple's conjugal relationship, being this latent and non-verbalized fear generating apprehension and discomfort, being sometimes perceived as the most difficult side of motherhood. The dating phase had now been replaced by caring for the children, as is clear in one participant's address: this period in which we spent sitting on the couch after dinner and went to the couch quietly and kisses here, kisses there, sitting still until going to sleep, is now flled with baths, and nursing one and nursing another, so it ceased to exist (E6).

Fearing withdrawal from work - work was an important part of their lives that was changed by motherhood. Since work is a reason for self-realization and personal development due to the financial autonomy provided, the opportunity for socialization and socialization has also been curtailed. Moving from an intense work activity, to a total or partial absence from work, to stay at home dedicating herself exclusively to the care required by motherhood was one of the great changes that required the participants of the study a great effort of adaptation. For some, too, the 
fear of being harmed by the prolonged withdrawal from employment during maternity leave was a cause for concern.

Feeling the weight of the masculine culture - The experience of maternity also came to question and expose the relationship between the couple and the role assumed by each one, and sometimes the individual repositioning of this role is unclear. Participants realized that caring for their children continues to be a social role attributed to women, and most have accepted it as a gender role. The acceptance of the role of mother as intrinsic to the feminine gender made the majority of the participants passively accept the detachment and comfort of their husbands, recognizing them as present but passive parents and accepting that their role was that is of a father of couch (E18), to preserve the relationship of the couple, stability and permanence of marriage, worrying not to overload them with household chores or even caring for the child. This unexpected side of family life was a revelation that overshadows and strengthens the hidden side of motherhood. However, as a result of the tacit acceptance of this role, they identified the husband's permissiveness towards the child as something natural, attributing and assuming for him the functions of educator and disciplinarian.

Removal from social life/friends - most participants referred to sadness and loneliness as being present in the first few months of motherhood experience. Restrictions or no longer having a social life, participating in social programs, leaving at night, being alone with the baby and living alone with the baby was one of the difficult aspects of living the time of motherhood. The loneliness and lack of sleep were related to the fear of leaving the house with the baby due to adverse weather conditions such as cold, rain or, on the contrary, excessive heat, as this could compromise the health and well-being of the baby. Also, the participants' concerns about the lack of immunity of the baby, because they did not have the vaccines and so being more susceptible to diseases limited the exits of the house until the baby had completed two months. The architectural barriers of buildings that hindered mobility and transportation such as stairs or a lack of lift and the fear of driving alone with the baby were also referred to as limiting factors regarding home leaving. Also, all the logistics that require a simple exit from home, due to the countless accessories that the baby needs (diapers, wipes, bottles, change of clothes), or because newborn's transport is very heavy and difficult to carry, made the exits of the house limited.

Caring for herself - Mothers felt the need not be dominated by the unexpected aspect of motherhood described previously in the category "Confronting the dark side" and decided to return to investing in themselves, to return to activities interrupted by the phenomenon of motherhood and were thus an essential source of their well-being in order to succeed in their multiple roles. The themes valued in the period from postpartum to return to work, essential for a healthy transition and good adaptation to motherhood, were: having time for herself, taking care of body and appearance; leaving home and resuming social activities of socializing and leisure, according to Figure 3.

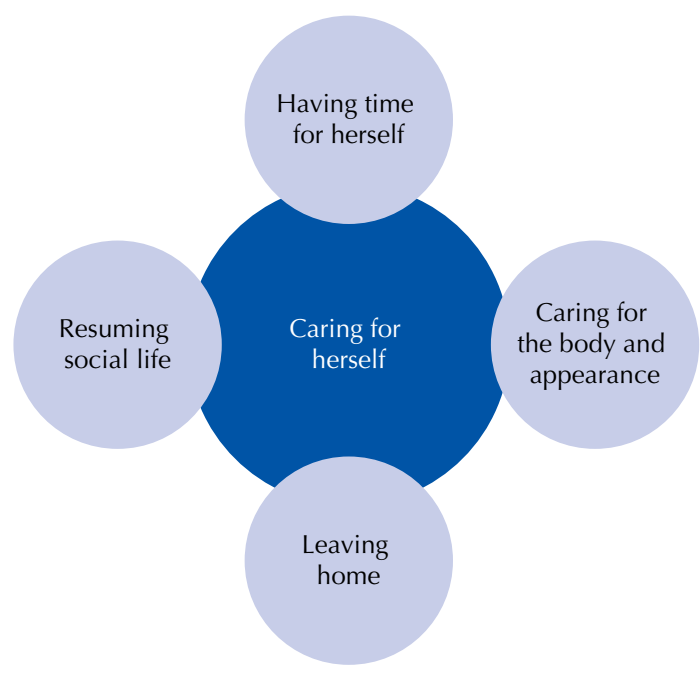

Figure 3 - Category Caring for herself and its subcategories.

Having time for herself - Spending time on herself was described as a way to gain well-being, to improve self-esteem and a desire to return to normal life. Participants note the importance of having time for themselves when they talk about the importance of looking after the body and its appearance. One of the participants commented this on one of the photos (Figure 4) that she took: it was the first time that I got a little time to deal with me; $M$. was asleep and I went to get my varnish and I was getting on my feet. That's what it symbolized - maybe the first little bit I had to devote to me a little bit, to feel that I was taking care of myself a little bit (E7).

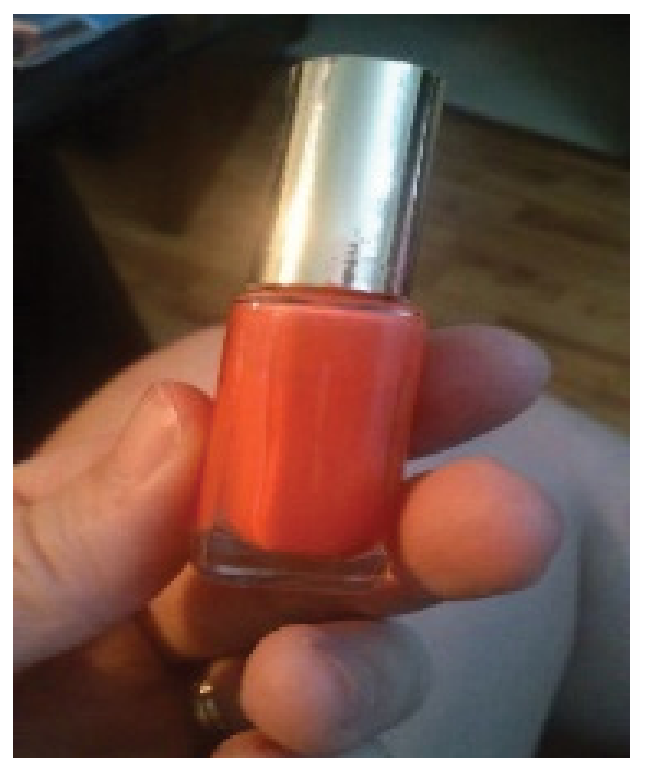

Figure 4 - Illustrative photo "Having time for herself".

Caring for the body and appearance - A way to feed positive emotions was, for the most part, embodied in taking care of the body and its appearance, again devoting time to the person, their body and spirit. Thus, details such as 
being able to take a shower in a relaxed manner, make-up, dress up in a presentable way as if they were going out, get their feet done, or buy new clothes were activities felt as part of caring for themselves and of their appearance. For some participants the need to feel cared for was less focused on aesthetic and appearance aspects, focusing more on psychological aspects, maintaining psychic well-being or preventing mental illness that would interfere with personal and family well-being. The strategies used by the participants were to stop feeling empty and improve depressive symptoms, such as going to the gym, doing acupuncture, doing massages to recover the physical part, putting things together that were out of place because of pregnancy, (E7), or doing psychotherapy to solve fears, strategies that were intentionally used.

Leaving home - At the beginning of the maternity leave, child care made staying at home much longer, sometimes consecutive days. For participants to leave home to resume social and leisure activity was a way to take care of themselves, so simply go to the mall, go shopping or meet friends were a source of energy and well-being. Leaving home became either a distraction or a leisure activity, or reinforced self-esteem as participants felt they had time for themselves. Staying at home with the consequent changes in the relationship with family and friends and colleagues was perceived as a loss and required a great effort of adaptation to reach a new concept of self and reach a healthy and balanced maternal identity.

Resuming social life - the fact that the participants are accustomed to having an intense social life through the professional relations and also the availability that a life without children implies, the conviviality with work colleagues or friends, suddenly interrupted by the birth of the child, meant that in the first few months the mother felt she did not have temporary availability for exits. Some of the participants reported a feeling of loss of liberty at the time of their hospitalization and early puerperium because they interrupted something very important that they had for granted - social life. Gradually the participants were finding strategies to adapt to the new reality and reported going back to social life, although with a different pattern, replacing dinners, cinemas and night exits by shorter programs during the day, preferably going out to the garden or playground.

For the participants to achieve well-being in interpersonal relationships, it meant resuming the social and leisure activities they had before they were mothers, such as leaving home, maintaining contact with work, re-living with family, friends or sharing experiences. Also retaking previous habits and everyday activities such as cooking or going to a Japanese restaurant was described as resuming a habit and satisfying a food taste that had been interrupted by the demands imposed by the pregnancy. Adapting to a new lifestyle in which habits were interrupted or diminished was perceived as a loss by the participants, so this obscure side of motherhood was not appreciated. Resuming social life was also to resume the daily activities that went back to work, because it is a way to leave home, to break social isolation, to resume or maintain contact and socializing with co-workers and or with the customers.

\section{DISCUSSION}

Confronting the obscure side of motherhood - At this stage of the process of Metamorphosis into a mother after the age of 35, participants became aware of their vulnerability associated with the transition by being confronted with this obscure side of motherhood. Doubts and difficulties experienced awakened feelings of inadequacy in role performance, that is, role inadequacy ${ }^{(14)}$ and feeling that their changing identity was fragile and even threatened. A woman who becomes a mother must necessarily modify several areas of her identity ${ }^{(21)}$, namely autonomy, physical appearance, sexuality and occupations, self-perception and relationship with others ${ }^{(22)}$. Maternity promotes identity changes because women are confronted with realities in juxtaposition with their ideals of motherhood ${ }^{(21)}$. To identify oneself as a mother and develop a maternal identity, involves the integration of culturally transmitted and internalized ideals about how women believe they should be a mother with the lived reality of motherhood ${ }^{(23)}$. However, it is not always easy to achieve this ideal, often with feelings of guilt, or even regret, often amplified by the socially transmitted idea that women should experience only positive feelings about motherhood ${ }^{(24)}$. Women in pondering motherhood seem to deliberately forget about maternal reality, dreaming of love and happiness, but ignoring the other face of motherhood "that is made of exhaustion, frustration, even loneliness, of alienation with his courtship of guilt" ${ }^{\prime 25)}$. In this process, response patterns were conditioned by personal and social conditions, and participants were confronted with various difficulties related to breastfeeding torment, total centering on the baby, fear of separation from the partner, and fear of withdrawal or even loss of employment. On the other hand, the assumption of the role of workers in today's society has placed women in conflict with the roles of wife and mother, which for the same author ${ }^{(25)}$ makes them face a triple contradiction: the first is social because if workers, companies make it difficult for them to reproach for successive maternities considering full-time mothers are undervalued and may be labeled as 'devoid of interest'; the second refers to the couple, because motherhood conflicts with conjugality because it does not foster a love life; and the third contradiction because the woman is divided between the love of the child and her personal desires, that is, the child conceived as a source of fulfillment may prove to be an obstacle to this same realization.

The Caring for herself category concerns the discussion of the response strategies and patterns used by the participants to address the difficulties experienced in the role of the mother as described in the "Confronting the Dark Side" category. At this stage, the response patterns and strategies used by the participants were aimed at recovering their identity that they had previously strived in order to rebalance, compensate and take care of themselves. It is an identity (re)valued by the need to rescue, cherish, 
rebalance and value the vulnerable and threatened identity of the previous phase. For the same reasons, it was at this stage, around the 2-4 months that the participants began to flexibly rebuild their daily lives, to be able to establish a routine with new schedules, new activities and new habits of social coexistence, determined and conditioned by needs of the child. In this phase of the process, the participants develop preventive or therapeutic actions of paper supplementation, to diminish, improve or prevent the insufficiency of the role, previously perceived by the participants or significant others, using for this strategies of clarification and role assumption/performance ${ }^{(14)}$. In a deeply hedonistic society ${ }^{(25)}$, to which we would add narcissistic, women when they become mothers cease to worry about themselves to forget about themselves, in favor of the care of the baby. Accustomed to be governed by the principles of pleasure and the cult of their own personality, today's highly competitive and demanding society has added the cult of image and beauty. Today's society is ruled by narcissism and hedonism ${ }^{(26)}$, and the care given to the body and image became associated with the notion of success. The stereotype of women with a successful career is a woman who associates her professional competence to an impeccable image of clothing, make-up, hair, hands and nails. The same author corroborates our opinion when he states that narcissism promoted the body "to the category of true object of cult" (26). According to $\operatorname{him}^{(26)}$, the social representation of the body underwent a deep change that went from alterity and materiality to the identification with the being-subject, that is, the person. For this reason, (with the personalization of the body), it gains dignity, must be respected and taken care of. The care that is given to keep it young, attractive, healthy, becomes an imperative ${ }^{(26)}$. However, in addition to this personalization of the body, narcissism has a social function of normalization and "the feverish interest we have in the body is by no means spontaneous and 'free', it obeys social

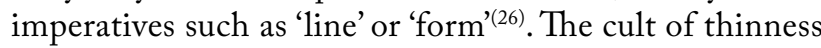
has succeeded over the cult of the corpulence of feminine forms, valued in previous times and societies for being associated with fecundity. Nowadays, being a mother is not the main role of women and the feminine identity is not built around reproduction. In our society, thinness is perceived positively as a sign of will, self-mastery, success, effectiveness and control, qualities generally attributed to men. The care of appearance ceased to be lived as a luxury only accessible to some women to become a duty, as well as beauty has become an imperative of modern times. The lost silhouette of the participants resulting from motherhood thus represents a serious blow to their identity that is urgent to repair, rehabilitate and rebuild. In this caring for oneself to resume daily habits and activities such as leaving home, resuming social activities of socializing and leisure or resuming work, were strategies used by the participants to face the loneliness and the overload experienced previously, and which assumed great relevance for feeling well-being in their experience of motherhood. For the participants of the study it was important to implement strategies of revaluation of their identity that they felt threatened in the previous phase. Achieving some intervals in the tasks inherent to motherhood by spending some time in activities such as being with friends, going to the gym, or simply leaving home were well-being strategies used by the participants and also referred ${ }^{(27)}$ during the first year. Other well-being strategies identified by the same author and that corroborate our findings were the search for help in particular from the mother and the husband himself and to try to organize themselves in the management of the daily tasks establishing a daily routine and making a planning of the activities. Hedonism cultivates spontaneity, exonerates free time, encourages each one to perform without constraints and to increase idleness, makes apology for movement, experimentation and initiative, which will lead to the well-being of the individual, rather than immobility and stability ${ }^{(26)}$. This need for movement was also revealed in the participants, namely in participating in other spheres of daily life already mentioned above and not only those confined to the house and the care of the baby.

\section{CONCLUSION}

Motherhood, because of its irreversibility, implies a new intense and lifelong relationship and, therefore, has a great impact on the personality of the woman. The study allowed us to conclude that in the process of "Metamorphosis in Mother after 35 years" two of the categories that integrate it - Confronting the Dark Side and Caring for Herself uncovered an obscure side of motherhood, ruled by difficulties experienced by mothers in the first two months after childbirth, unknown to mothers. At this stage, participants were confronted with various difficulties related to breastfeeding torment, total focus on the baby, fear of separation from the partner, and fear of withdrawal or even loss of employment, which caused feelings of inadequacy to participants in the performance of the role and the feeling that their changing identity was threatened. To overcome these perceived difficulties in role performance, the response patterns and strategies used by the participants were aimed at restoring their identity that they had previously strived to rebalance, compensate, and care for themselves. It was around 2-4 months that the participants began to flexibly rebuild their daily lives, to be able to establish a routine with new schedules, new activities and new habits of social coexistence, determined and conditioned by the needs of the child. Lack of gender equality in the division of household chores and childcare were also factors mentioned as contributors to the confrontation with the dark side of motherhood, postponing or deciding not to have more children.

Qualitative research, in this case, the GT, proved to be a methodology that allowed to uncover the process of metamorphosis of the woman into mother after 35 years old, and thus improving the understanding of the phenomenon. A better knowledge of this, will allow to provide more comprehensive and holistic nursing care in the maternity. 
RESUMO

Objetivo: Compreender o processo de transição de mulheres que passam pela situação de maternidade após os 35 anos de idade. Método: Utilizamos a metodologia construtivista da Grounded Theory (teoria fundamentada em dados) na elaboração da pesquisa, coleta de dados e análise. Resultados: Os resultados permitiram a construção de um modelo abrangente da transição para uma experiência de maternidade após os 35 anos de idade, chamado "Metamorfose na Mãe". Esse processo integra várias categorias, remetendo-se a apenas duas delas neste artigo: "Confrontando o lado escuro" e "Cuidando de si mesma". Conclusão: Dos resultados alcançados, destacamos as dificuldades vivenciadas pelas mães ao redor do segundo mês, que revelaram um lado obscuro da maternidade, desconhecido para as mães, e a necessidade de cuidar-se de si mesmas para superar essas dificuldades.

\section{DESCRITORES}

Idade Materna; Identificação Social; Enfermagem Obstétrica.

\section{RESUMEN}

Objetivo: Comprender el proceso de transición de mujeres que pasan por la situación de maternidad tras los 35 años de edad. Método: Utilizamos la metodología constructivista de la Grounded Theory (teoría fundada en los datos) en el diseño de la investigación, recolección de datos y análisis. Resultados: Los resultados permitieron la construcción de un modelo amplio de la transición hacia una experiencia de maternidad después de los 35 años de edad, llamado "Metamorfosis en la Madre". Dicho proceso integra distintas categorías, remitiéndose a solo dos de ellas en este artículo: "Confrontando el lado oscuro" y "Cuidándose a sí misma". Conclusión: De los resultados alcanzados, destacamos las dificultades vividas por las madres alrededor del segundo mes, que desvelaron un lado obscuro de la maternidad, desconocido de la madres, y la necesidad de cuidarse a sí mismas a fin de superar dichas dificultades.

\section{DESCRIPTORES}

Edad Materna; Identificación Social; Enfermería Obstétrica.

\section{REFERENCES}

1. Carolan M, Frankowska D. Advanced maternal age and adverse perinatal outcome: a review of the evidence. Midwifery. 2011;27(6):793801. DOI: http://dx.doi.org/10.1016/j.midw.2010.07.006

2. Beets G. The demography of the age at first birth: the close relationship between having children and posponment. In: Beets G, Shippers J, Velde ER, editors. The future of motherhood in western societies: late fertility and its costs. London: Springer; 2011. p. 61-90.

3. Oliveira M, Sousa W, Pimentel J, Santos K, Maia M. Advanced age pregnancy: review of literature. Rev Enf UFPE On line. 2012;6(6):1413-21.

4. Mendes F, Infante P, Afonso A, Maiciel A, Ribeiro F, Tomé L, et al. Determinantes da fecundidade em Portugal [Internet]. Lisboa; 2016 [citado 2018 mar. 15]. Disponível em: https://www.ffms.pt/publicacoes/grupo-estudos/1517/determinantes-da-fecundidade-em-portugal

5. Portugal. Instituto Nacional de Estatística. Nados-vivos de mães residentes em Portugal: total e por grupo etário da mãe. Lisboa; 2017.

6. Organization for Economic Cooperation and Development (OECD). Families are changing [Internet]. Paris: OECD; 2011 [cited 2018 June 16]. Available from: https://www.oecd.org/els/soc/47701118.pdf

7. Daly I, Bewley S. Reproductive ageing and conflicting clocks : King Midas ' touch. Reprod Biomed Online [Internet]. 2013 [cited 2018 Mar 15];27(6):722-32. Available from: http://dx.doi.org/10.1016/j.rbmo.2013.09.012

8. Nelson SM, Telfer EE, Anderson RA. The ageing ovary and uterus: new biological insights. Hum Reprod Update. 2013;19(1):67-83.

9. Santos MA, Lopes MA, Botelho MA. Photovoice as a method of data collection in the study of motherhood over the age of 35: the power of images. In: Costa AP, Reis LP, Souza FN, Moreira A, editors. Computer supported qualitative research, advances in intelligent systems and computing. New York: Springer; 2018. p. 316-26.

10. Kenny L, Lavender T, McNamee R, O'Neill S, Mills T. Advanced maternal age and adverse pregnancy outcome: evidence from a large contemporary cohort. PLoS One. 2013;8(2):e56583.

11. Lisonkova S, Sheps SB, Janssen PA, Lee SK, Dahlgren L, Macnab YC, et al. Birth outcomes among older mothers in rural versus urban areas: a residence-based approach. J Rural Health. 2011;27(2):211-9.

12. Mercer R. Becoming a mother versus maternal role attainment. J Nurs Sch. 2004;36(3):226-32.

13. Meleis Al, Sawyer LM, Im E-O, Messias, DeAnne K. H. Schumacher K. Transitions Theory: middle range and specific theories in nursing and practice. New York: Springer; 2010. p. 52-72.

14. Meleis Al. Tansitions theory: midle range and situation specific theories in nursing research and practice. New York: Springer; 2010.

15. Charmaz K. Constructing grounded theory. 2nd ed. London: Sage; 2014.

16. Wertz FJ, Charmaz K, McMullen L, Josselson R, Anderson R, McSpadden E. Five ways of doing qualitative analysis: phenomenological psychology, grounded theory, discourse analysis, narrative research, and intuitive inquiry. London: Guilford; 2011.

17. Flick U. An introduction to qualitative research. London: Sage; 2014.

18. Ramalho R, Adams P, Huggard P, Hoare K. Literature review and constructivist grounded theory methodology. Forum Qual Soc Res. 2015;16(3):1-13.

19. Wang C, Burris MA. Photovoice: concept, methodology, and use for participatory needs assessment. Health Educ Behav. 1997;24(3):369-87.

20. Beck CT. Qualitative research: The evaluation of its credibility, fittingness, and auditability. West J Nurs Res. 1993;15(2):263-6.

21. Laney EK, Hall MEL, Anderson TL, Willingham MM. Becoming a mother: the influence of motherhood on women's identity development. Int J Theory Res. 2015;15(2):126-45. 
22. Steinberg Z. Donning the mask of motherhood: a defensive strategy, a developmental search. Stud Gender Sex. 2005;6(2):173-98.

23. Choi P, Henshaw C, Baker S, Tree J. Supermum, superwife, supereverything: performing femininity in the transition to motherhood. J Reprod Infant Psychol. 2005;23(2):167-80.

24. Donath O. Mães arrependidas. Lisboa: Bertrand; 2017.

25. Badinter E. O conflito: a mulher e a mãe. Lisboa: Relógio D’Água; 2010.

26. Lipovetsky G. A era do vazio: ensaios sobre o individualismo contemporâneo. Lisboa: Edições 70; 2017.

27. Currie J. Managing motherhood: strategies used by new mothers to maintain perceptions of wellness. Health Care Women Int. 2009;30(7):655-70.

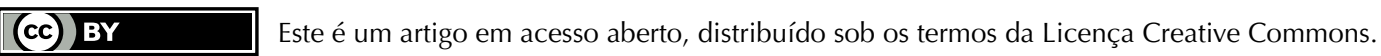

